\title{
A new twist on the graduate student journal club: Using a topic - centered approach to promote student engagement
}

\section{Authors: Diane Bimczok and John Graves}

This is the peer reviewed version of the following article: [Bimczok, D., and Graves, J. (2020). A new twist on the graduate student journal club: Using a topic - centered approach to promote student engagement. Biochemistry and Molecular Biology Education 48, 262-268.], which has been published in final form at https://doi.org/10.1002/bmb.21337. This article may be used for non-commercial purposes in accordance with Wiley Terms and Conditions for Use of SelfArchived Versions.

Bimczok, Diane, and John Graves. "A New Twist on the Graduate Student Journal Club: Using a Topic - centered Approach to Promote Student Engagement." Biochemistry and Molecular Biology Education 48, no. 3 (February 20, 2020): 262-268. doi:10.1002/bmb.21337. 


\section{A new twist on the graduate student journal club: using a topic-centered approach to promote student engagement}

Short title: Reversed graduate student journal club format

Keywords: $\quad$ graduate curriculum, student-centered, primary literature

Diane Bimczok ${ }^{1 *}$ and John Graves ${ }^{2}$

${ }^{1}$ Department of Microbiology and Immunology, Montana State University, Bozeman, MT, 59717

${ }^{2}$ Master of Science in Science Education Program, Montana State University; Bozeman, MT, 59717

*Corresponding author. Email: $\underline{\text { Diane.bimczok@montana.edu }}$

Phone: 406-994-4928 


\section{Abstract}

Journal clubs are widely used as an educational tool in graduate life science programs. In journal clubs, students are assigned to read specific journal articles to achieve a broad knowledge in their field of study and to gain competence in reading and assessing scientific publications. However, students often show low motivation to read assigned articles, and under-prepared students contribute little to in-class discussions. In order to promote student engagement in graduatelevel journal clubs, we used an inverted, student-centered format that focuses on a scientific question or topic rather than specific publications. Both the weekly topics and the scientific publications were selected by the students and focused on aspects of the students' thesis research. For each weekly topic, students were asked to find papers, read the papers and summarize the findings during class, which led to the presentation of a variety of approaches and viewpoints. This approach trained students in literature search, focused reading and oral presentation skills and provided a broad overview of the research in the selected topic areas. Student feedback showed a high level of acceptance of the new format. We propose this inverted journal club format as a useful alternative to traditional formats, because it focuses on a different scientific skill set and leads to increased student engagement through its student-centered approach. 


\section{Introduction and Background}

The journal club as an instructional format is widely used in life science and medical education $[1,2]$. Journal clubs are formal or non-formal groups of individuals that meet on a regular basis to discuss recent or key scientific articles published in peer-reviewed journals [3]. A typical journal club involves the selection of one specific journal article by a faculty member or senior participant. The participants read the selected article in preparation for the meeting and then review and discuss the methodology, results, conclusions and impact of the paper with the group. Journal clubs thus allow participants to learn about novel discoveries and methods, to practice sharing and evaluating scientific findings, and to engage in scientific discussions, often across different disciplines. Notably, the journal club strategy also aligns with the Next Generation Science Standard (NGSS) practice of engaging in argument from evidence [4] by providing a format to fully engage in sense-making and discourse, key components of argumentation.

The journal club format has a century long tradition, with records on medical journal clubs in the United States dating back to 1875 [1]. Originally, journal clubs were a venue for physicians to share information from medical journal articles, since access to the medical literature at that time was limited, and to discuss the impact of new research findings on clinical practice. The rationale for conducting journal clubs has since shifted to the education of trainees in the critical appraisal of the scientific literature. In life science doctoral education, journal clubs are an integral part of the graduate curriculum and have become sufficiently popular and common to be considered a "signature pedagogy", along with laboratory rotations [2]. Signature pedagogies are the "characteristic forms of teaching and learning [...] that organize the fundamental ways in 
which future practitioners are educated for their new professions" (Shulman, 2005, p. 52 [5]). Since specialty textbooks often are not available, may be prohibitively expensive and frequently do not include the most up-to-date discoveries, many advanced graduate level life science courses also revolve around the reading and interpretation of recently published, peer-reviewed journal articles. Anecdotal reports, the authors' personal experience and an online search of current course catalogues strongly suggest that the majority of microbiology and immunology graduate programs in the US utilize journal clubs and literature-based courses in their curricula. By engaging with a variety of key or recently published journal articles, graduate students are exposed to different experimental methods and technological approaches, learn about presentation and interpretation of data, become familiar with scientific writing styles, and practice critically assessing the work of other scientists. Through presentation and discussion of scientific articles, students compare and evaluate competing arguments, claims, evidence and reasoning. In contrast to undergraduate students who participate in literature-based courses, graduate students generally are expected to be familiar with the scientific process that leads to a published manuscript and have a high level of content knowledge. A meta-analysis on publications regarding the effectiveness of journal clubs revealed that trainees involved in journal clubs show improved reading habits and better utilization of findings from the literature in their daily work [3]. Journal clubs thus enable students to develop a broad knowledge in their field of science [6] and develop key competencies of a successful scientist.

\section{Challenges associated with traditional journal club formats: The traditional approach to} conducting journal clubs, which consists of the students reading and talking about one assigned article, does not ideally promote student engagement and learning $[2,6,7]$. Students often show a limited motivation to read complex articles that are outside their immediate area of interest. 
Lack of motivation may result in failure to read the assigned articles and in under-prepared students who contribute very little to the in-class discussions $[2,7]$. When faculty members select articles and lead the discussions, this generally results in a greater number of interactions between educator and students rather than amongst the students, limiting constructive and cross-disciplinary discussions [6]. Under-preparation is especially common if only one or two students are assigned to present the article during class time. In addition, graduate students may become fatigued with the overuse of article based-courses as the major teaching approach in their graduate education if they participate in other advanced, graduate-level courses that utilize a similar format. Although it is widely accepted that well-defined learning objectives improve teaching outcomes, students in journal club classes are commonly assigned to read an article without being provided any specific guidelines or goals, which further limits student learning and decreases motivation [8]. To overcome these challenges, we have developed a new student- and topic-centered format for conducting graduate life science journal club classes, where students selected both the topics to be covered and the publications to be read, and each student gave a mini-presentation about their paper of choice for each topic.

\section{Development of a topic-based "inverted" journal club format to promote student engagement}

\section{and learning}

We developed a topic- and student-centered approach to conducting graduate level journal clubs that addresses several challenges commonly associated with traditional journal clubs, as shown in Table 1 and detailed below. The Ph.D. program in Microbiology and Immunology at Montana State University requires that, in addition to their thesis research, all 
students complete a minimum of $25 \mathrm{~h}$ of coursework, which includes participation in a 1-credit journal club course during each semester in residence. Depending on the student's field of study, three parallel journal club courses focused on different topics are offered each semester. Our new format was used in our graduate biomedical journal club (MB592) during two consecutive years (2016 and 2017).

The major characteristics of our course design were that (1) each class session focused on one specific scientific question or topic rather than a particular article; (2) topics were selected by the students, with instructor approval, and related to the students' thesis research; (3) instead of everyone reading the same article, each student chose a different article to read for each class session, leading to the presentation of a variety of different papers and viewpoints for each topic; (4) during class, each student summarized how their chosen article addressed the question and what methodological approach was used.

(1) Topic-specific approach: Focusing on a topic or scientific problems rather than a specific article provided a clear learning goal for the students, so that students were able to focus their learning efforts and read the selected article with a specific purpose in mind. According to goal setting theory, clearly defined goals are strong motivators that lead to significantly higher performance in a variety of settings [9]. Thus, our topic-based approach likely improved both student engagement and learning outcomes. Topic-based approaches have been previously proposed by Rodriguez and Hawley-Molloy [7] and Khan and Gee [8], who used clinical problems as a basis for internal medicine residents' journal clubs, and lyengar, et al. [6], who used selection and summarization of a paper in response to a scientific problem as the final exam task in an advanced cell signaling class. Similarly, the C.R.E.A.T.E. approach, proposed as a novel teaching 
tool in undergraduate science education, utilizes a sequence of multiple papers either from a single lab or focused on a single topic [10]. Khan and Gee [8] state that focusing on a relevant question provides a motivational context and conveys to importance of literature appraisal as a crucial career skill to the trainees. Rodriguez and Hawley-Molloy [7] reported that a topic-focused approach was preferred over the traditional format and led to increased engagement and a higher number of papers read by the trainees.

(2) Topic selection by students: The second modification that we implemented was to place the topic selection in the hands of the students, who took turns selecting research topics. Sidorov [11], who conducted a survey on journal clubs in internal medicine residency programs concluded that journal clubs were more successful with reduced faculty involvement. In our journal club, the role of the faculty was limited to approving the topics and providing guidance on the formulation of the research questions and moderating the in-class discussion. Students were encouraged to select topics that were directly related to their personal research interests and dissertation work. At the start of each journal club meeting, the student whose topic was being discussed gave a short summary on their research and how the research question to be discussed was relevant to their work, providing additional context and background. Focusing on topics relevant to their own or their peers' work created a personal connection with the material and further increased student motivation and engagement, which in turn facilitates learning [12]. Importantly, the student whose topic was discussed during a specific class period immediately benefitted from the input provided by their peers. Moreover, learning about the other students' research project sparked scientific discussions and collaborations between the students. 
(3) Individual selection of articles by students: In addition to selecting the topics for the class, students also were charged with selecting the articles that they read and presented for class, placing additional responsibility into the students' hands. This approach likely increased the students' feeling of autonomy and gave them ownership of their work, which, according to selfdetermination theory additionally increases motivation $[13,14]$. Having each student identify a publication that best answered the research question also introduced a competitive element to the class. Students appeared highly motivated to find publications that had the potential to advance the projects of their peers. The competitive atmosphere created by letting students find appropriate publications was also mentioned by Rodriguez and Hawley-Molloy [7], who went even further by dividing medical residents into teams and awarding a trophy for the team that was judged to select the best papers. In searching for publications to answer the research questions, students practiced relevant literature search skills. Different strategies for finding published articles on a topic were included as part of the in-class discussion. Moreover, the selection of different articles by students with different interests and backgrounds led to the presentation of a wider spectrum of view points and methodological approaches on a given topic and thus gave breadth to the in-class discussions. Since students were able to choose papers that they could relate to and were able to comprehend, our approach also provided an increased opportunity for the students to build on existing knowledge.

(4) Oral mini-presentations: During each class session, every student gave a brief, 5- to 7minute oral summary of their chosen article. Students were provided with written guidelines on the suggested format for the mini-presentations. Presentations were to include a description of the experimental approach used, the key results of the article, a discussion of how the article answered the research question and comments on the perceived quality of the publication. This 
allowed students to practice their public speaking skills in a brief presentation format, which requires a concise, coherent and comprehensible summarization of key ideas. A similar approach is used in the Three Minute Thesis Competition that was first developed in 2008 by the University of Queensland and that has since become popular across the world for training graduate students in communicating their science [15]. Notably, training students in communicating scientific information in a variety of settings and formats is also an important NGSS Science and Engineering Practice [4]. Having each student give a presentation during each session ensured that every student was prepared for and participated in class, and it also prevented specific students from dominating the discussion. In our class, students also were not allowed to use visual aids such as power point presentations, so that they had to communicate all relevant information verbally. Thus, students became comfortable in concisely presenting complex scientific ideas in a manner that is rarely taught in classroom settings, but that is a relevant skill for successful networking with scientific colleagues.

\section{Experiences with the "inverted" journal club format in a Ph.D. program in Microbiology and}

\section{Immunology:}

We used the inverted, student centered journal club format described above in a graduate level biomedical journal club course in the Department of Microbiology and Immunology at Montana State University. The course was taught in fall 2016 and 2017 by a single instructor (DB) and was attended by 9 and 7 students, respectively. Of the students that experienced the new journal club format, 6 out of 9 students in 2016 and all 7 of the 7 students in 2017 had previously participated in a "traditional" journal club in our department. 
Students took turns selecting topics and communicated with the instructor when formulating their research questions. Student-selected articles for each class period were shared on a cloud drive, so that every student had access to each article. Sample topics proposed by students are given in Table 2 . The relatively small class size ( $7-9$ students) allowed $5-7$ min short oral presentations with brief discussions for each paper. Thus, each student in the course talked for at least 5 min each time the class met. A timer was used to ensure that the students did not exceed their allotted time.

Journal club classes conducted in the new format were evaluated using standard MSU evaluation forms (see supplemental material). Analysis and publication of information from the anonymized course evaluation forms was designated as exempt by the MSU Institutional Review Board in accordance with CFR 46, section 101, paragraph (b) (2) (protocol \#DB052418-EX). The course received excellent student feedback, with $4.74 \pm 0.48$ out of 5 (response rate $8 / 9$ ) and $4.98 \pm 0.05$ out of 5 (response rate 6/7) for 2016 and 2017, respectively. Notably, within the same department and time period, student evaluations for the new, topic-centered were moderately higher than the ratings for traditional-format journal clubs, where all students were assigned one specific publication to read (Table 3). Positive comments included that letting "the students run the class was an excellent way to stimulate interest and excitement in the discussions", that they "feel more engaged choosing [their] own article and learn more hearing other student's selections". One student stated that "this [was] the first time in 4 semesters of attending journal club that I felt like it benefitted me". Multiple students commented that they found the reversed format more productive. In addition, the students commented that they enjoyed learning more about the research of their peers and benefitted from input of other students with different 
literature search strategies. One student commented that the increased breadth, but lack of depth was a disadvantage.

From the point of view of the instructor, one major advantage of our approach was that every student had to present during each class period, which required all students to be prepared every time. Throughout the semester, students improved the quality of their brief oral summaries and appeared to gain confidence in verbally summarizing the major results from a publication. Students overall seemed engaged with the class, and some participants were obviously excited about sharing their findings with the person who had picked the question. A more rigorously designed and larger study with matched control groups to objectively measure student motivation, literature search skills, scientific reading skills and presentation skills over the course of the semester by survey instruments or classroom observations could solidify the validity of our observations.

\section{Discussion and Lessons Learned}

In summary, our format promotes a broad discussion of scientific topics through the presentation of different approaches and viewpoints, provides training in literature search and public speaking skills and may also create some much-needed variation in graduate level courses. As a lesson learned, one crucial responsibility of the instructor was to assist the students in formulating the research topics or questions and providing a summary of the research context, so that the other students had a clear goal for their literature search. If the topic was too broad, papers selected by the students often were not relevant, but if the topic was too narrow, only a limited number of relevant papers were available, limiting the scope of the discussion. Also, 
instructors should consider providing a sample paper summary at the beginning of the course to help students in the preparation and presentation of their own five-minute summaries. Notably, due to the presentation of multiple different articles, the topic centered format lends breadth to the discussion, but limits the depth at which individual aspects of specific papers can be discussed. Moreover, since the number of publications that can be presented and discussed during a typical one-hour class period is limited, this places a limit on the number of students that can participate. However, this could be remedied by letting students work together in small teams and by altering the course schedule.

As Sidorov determined in 1995 [11], journal clubs with lower faculty involvement are more effective. "Flipped" classroom models generally move traditional classroom activities, such as lecture, readings and lab preparation, to an online format for students to complete before attending class. This affords more time in class for active learning through discussion, investigations and cooperative problem solving $[16,17]$. Since participants are required to engage with instructional content, i.e., the publications, before discussing concepts in class all journal clubs technically follow a "flipped classroom" model $[18,19]$. We placed additional responsibility into the students' hands by also letting students pick the instructional topics. We considered our approach "inverted", because each class session focused on a topic that was discussed using multiple publications, rather than the discussion of one single publication that is common in traditional journal clubs. Our inverted journal club format likely could be further improved by designating more class time to an overall discussion and evaluation of all papers presented to enable students to integrate the information from the different studies. Other authors have suggested improving the flipped classroom approach in journal clubs by incorporating technology. Thus, Ferguson et al. [20] used the social media service Twitter in a 
nursing journal club to conduct and record in-class discussions about journal club papers. In a journal club for family medicine residents, participants were required to complete online modules before the class sessions, which involved answering questions about the papers in a discussion forum [21]. Other teaching strategies to promote student understanding of primary literature developed in recent years include the use of templates ("Figure Facts") to encourage students to focus on the results presented in each figure of a publication [22], the C.R.E.A.T.E. approach, which encourages students to Consider, Read, Elucidate hypotheses, Analyze and interpret data, and Think of the next Experiment $[10,23]$ or POGIL (Process Oriented Guided Inquiry Learning), which involves group-based learning in self-managed collaborative teams [24]. Our topic- and student-centered approach is easily compatible with any of these strategies.

\section{Conclusions}

In conclusion, letting students choose the topics to be discussed, allowing each student individually to select a publication to read and requiring each student to give a presentation during each class has the potential to increase student engagement in graduate-level journal club classes. Our novel approach to journal club classes may be a useful alternative to the traditional journal club format and is designed to teach a number of relevant career skills that are not generally emphasized in traditional journal club settings. 


\section{Acknowledgements}

This study was supported by startup funds from Montana State University to Dr. Bimczok.

The support of Dr. M. Jutila in establishing the new teaching format is gratefully acknowledged.

The authors declare no conflict of interest. 
Table 1: Common issues with JCs and how the new format addresses them

\begin{tabular}{|c|c|}
\hline Issue & Method \\
\hline Low student motivation & $\begin{array}{l}\text { Topics related to students' research create connection with the } \\
\text { material, competitive aspect in finding the "best" paper }\end{array}$ \\
\hline $\begin{array}{l}\text { Students do not read } \\
\text { articles }\end{array}$ & $\begin{array}{l}\text { Every student has to select an article to read and present a } \\
\text { summary during class }\end{array}$ \\
\hline $\begin{array}{l}\text { Few students dominate } \\
\text { discussion }\end{array}$ & $\begin{array}{l}\text { Every student is required to summarize one article during each } \\
\text { class period }\end{array}$ \\
\hline $\begin{array}{l}\text { Course does not build on } \\
\text { existing knowledge }\end{array}$ & Students select articles they can relate to \\
\hline Lack of learning objectives & Focus on specific scientific question provides clear goals \\
\hline
\end{tabular}

Table 2: Sample student-selected topics for a journal club in Microbiology and Immunology

How do mast cells in the lung environment interact with viral material and communicate with other cell populations during influenza A infection?

What chemokines or chemotactic factors are expressed by the gastric epithelium that may attract dendritic cells?

What is known about the role of heat shock proteins (aka the misfolded protein response) in insect host-pathogen interactions?

Is there any direct evidence that when the 5'-ectonucleotidase CD73 is knocked out, there is a change in extracellular and/or intracellular adenosine-containing metabolite concentrations? How well does understanding pathogen infection at the within-host level predict populationlevel disease dynamics?

Are there any interactions between the NF-kB signaling pathway and nuclear hormone receptors such as the aryl hydrocarbon receptor or pregnane $\mathrm{X}$ receptor?

Table 3: Student evaluations for traditional biomedical journal clubs compared to the new student- and topic-centered format.

\begin{tabular}{llll}
\hline Course format & Year taught & Evaluations received & Course rating* \\
\hline Traditional & Fall 2015 & $14 / 19$ & $4.00 \pm 1.01$ \\
Traditional & Spring 2016 & $5 / 5$ & $4.34 \pm 0.60$ \\
Traditional & Spring 2017 & $18 / 20$ & $4.29 \pm 0.79$ \\
Topic-centered & Fall 2016 & $8 / 9$ & $4.74 \pm 0.48$ \\
Topic-centered & Fall 2017 & $6 / 7$ & $4.98 \pm 0.05$ \\
\hline
\end{tabular}

* Course ratings: 0 (poor) to 5 (excellent). 


\section{$\underline{\text { References }}$}

[1] M. Linzer, "The journal club and medical education: over one hundred years of unrecorded history," Postgrad Med J, vol. 63, no. 740, pp. 475-8, Jun 1987.

[2] C. M. Golde, "Adapting signature pedagogies in doctoral education The case of teaching how to work with the literature," in The Routledge Doctoral Supervisor's Companion: Routledge, 2010, pp. 124-138.

[3] J. O. Ebbert, V. M. Montori, and H. J. Schultz, "The journal club in postgraduate medical education: a systematic review," Med Teach, vol. 23, no. 5, pp. 455-61, 2001, doi: $10.1080 / 01421590120075670$.

[4] NGSS Lead States., Next Generation Science Standards : for states, by states. Washington, D.C.: National Academies Press, 2013.

[5] L. S. Shulman, "Signature pedagogies in the professions," Daedalus, vol. 134, no. 3, pp. 5259, 2005, doi: 10.1162/0011526054622015.

[6] R. Iyengar et al., "Inquiry learning. Integrating content detail and critical reasoning by peer review," Science, vol. 319, no. 5867, pp. 1189-90, Feb 29 2008, doi:

10.1126/science.1149875.

[7] R. G. Rodriguez and J. S. Hawley-Molloy, "Revamping Journal Club for the Millennial Learner," J Grad Med Educ, vol. 9, no. 3, pp. 377-378, Jun 2017, doi: 10.4300/JGME-D-1600667.1.

[8] K. S. Khan and H. Gee, "A new approach to teaching and learning in journal club," (in English), Medical Teacher, vol. 21, no. 3, pp. 289-293, May 1999.

[9] T. Brown and G. Latham, "The effects of behavioral outcome goals, learning goals, and urging people to do their best on an individual's teamwork behaviour in a group problemsolving task," Canadian Journal of Behavioural Science, vol. 34, no. 4, pp. 276-285, 2002.

[10] L. M. Stevens and S. G. Hoskins, "The CREATE Strategy for Intensive Analysis of Primary Literature Can Be Used Effectively by Newly Trained Faculty to Produce Multiple Gains in Diverse Students," CBE Life Sci Educ, vol. 13, no. 2, pp. 224-42, Summer 2014, doi: 10.1187/cbe.13-12-0239.

[11] J. Sidorov, "How are internal medicine residency journal clubs organized, and what makes them successful?," Arch Intern Med, vol. 155, no. 11, pp. 1193-7, Jun 121995.

[12] S. Hidi and K. A. Renninger, "The four-phase model of interest development," (in English), Educ Psychol-Us, vol. 41, no. 2, pp. 111-127, Spr 2006, doi: DOI

10.1207/s15326985ep4102_4. 
[13] E. L. Deci, R. J. Vallerand, L. G. Pelletier, and R. M. Ryan, "Motivation and Education - the Self-Determination Perspective," (in English), Educ Psychol-Us, vol. 26, no. 3-4, pp. 325346, Sum-Fal 1991, doi: DOI 10.1207/s15326985ep2603\&4_6.

[14] D. I. Hanauer, J. Frederick, B. Fotinakes, and S. A. Strobel, "Linguistic analysis of project ownership for undergraduate research experiences," (in English), CBE Life Sci Educ, vol. 11 , no. 4, pp. 378-85, Winter 2012, doi: 10.1187/cbe.12-04-0043.

[15] J. W. Bandler and E. M. Kiley, "In the First Few Blinks of an Eye: The Basics of Engaging Presentations," (in English), IEEE Microwave Magazine, vol. 18, no. 2, pp. 112-120, MarApr 2017, doi: 10.1109/Mmm.2016.2636681.

[16] C. A. Giuliano and L. R. Moser, "Evaluation of a Flipped Drug Literature Evaluation Course," Am J Pharm Educ, vol. 80, no. 4, p. 66, May 25 2016, doi: 10.5688/ajpe80466.

[17] F. Ozdamli and G. Asiksoy, "Flipped Classroom Approach," World Journal on Educational Technology: Current Issues, vol. 8, no. 2, pp. 98-105, 2016.

[18] S. J. DeLozier and M. G. Rhodes, "Flipped Classrooms: a Review of Key Ideas and Recommendations for Practice," (in English), Educ Psychol Rev, vol. 29, no. 1, pp. 141-151, Mar 2017, doi: 10.1007/s10648-015-9356-9.

[19] J. O'Flaherty, C. Phillips, S. Karanicolas, C. Snelling, and T. Winning, "The use of flipped classrooms in higher education: A scoping review (vol 25, pg 85, 2015)," (in English), Internet High Educ, vol. 27, pp. 90-90, Oct 2015, doi: 10.1016/j.iheduc.2015.05.001.

[20] C. Ferguson, M. DiGiacomo, L. Gholizadeh, L. E. Ferguson, and L. D. Hickman, "The integration and evaluation of a social-media facilitated journal club to enhance the student learning experience of evidence-based practice: A case study," Nurse Educ Today, vol. 48, pp. 123-128, Jan 2017, doi: 10.1016/j.nedt.2016.10.002.

[21] S. Y. Rucker, Z. Ozdogan, and M. Al Achkar, "Flipped classroom model for learning evidence-based medicine," Adv Med Educ Pract, vol. 8, pp. 619-625, 2017, doi:

10.2147/AMEP.S142233.

[22] J. E. Round and A. M. Campbell, "Figure facts: encouraging undergraduates to take a datacentered approach to reading primary literature," CBE Life Sci Educ, vol. 12, no. 1, pp. 3946, Spring 2013, doi: 10.1187/cbe.11-07-0057.

[23] S. G. Hoskins, L. M. Stevens, and R. H. Nehm, "Selective use of the primary literature transforms the classroom into a virtual laboratory," Genetics, vol. 176, no. 3, pp. 1381-9, Jul 2007, doi: 10.1534/genetics.107.071183.

[24] T. A. Murray, "Teaching students to read the primary literature using POGIL activities," Biochem Mol Biol Educ, vol. 42, no. 2, pp. 165-73, Mar-Apr 2014, doi: 10.1002/bmb.20765. 
